\title{
Conselho de Segurança Alimentar e Nutricional: análise do controle social sobre a Política Estadual de Segurança Alimentar e Nutricional no Estado do Espírito Santo
}

\author{
Food and Nutritional Security Council: analysis of the social \\ control over the Food and Nutritional Security State Policy in \\ the State of Espírito Santo
}

\author{
Renata Lopes de Siqueira \\ Doutoranda em Ciência da Nutrição pela Universidade Federal de \\ Viçosa. Professora Titular do curso de Nutrição da Faculdade de \\ Ciências Integradas do Espírito Santo. \\ Endereço: Rua Floriano Peixoto, 66, CEP 36570-000, Viçosa, Minas \\ Gerais, Brasil. \\ E-mail: renata.educacaoळgmail.com \\ Débora de Andrade Fonseca \\ Acadêmica do Curso de Nutrição da Faculdade de Ciências Inte- \\ gradas do Espírito Santo. \\ Endereço: Rua Inácio Pessoa, 15, Caratoíra, CEP 29025-666, Vitória, \\ Espírito Santo, Brasil. \\ E-mail: mariananutryळhotmail.com
}

\section{Mariana Nogueira Viana}

Acadêmica do Curso de Nutrição da Faculdade de Ciências Integradas do Espírito Santo.

Endereço: Rua Inácio Pessoa, 15, Caratoíra, CEP 29025-666, Vitória, Espírito Santo, Brasil.

E-mail: mariananutryळhotmail.com

Túlio da Silva Junqueira

Doutorando em Ciência da Nutrição pela Universidade Federal de Viçosa; Professor Assistente do Curso de Graduação em Medicina do Centro Universitário Serra dos Órgãos.

Endereço: Rua Ana Koester, 10, apto.102, CEP 36570-000, Centro, Viçosa, Minas Gerais, Brasil.

E-mail: tuliojunqueira®gmail.com

Rita de Cássia Lanes Ribeiro

Doutora em Saúde Pública. Professora Associada do Departamento de Nutrição da Universidade Federal de Viçosa.

Endereço: Av. PH Rholfs, s/n, CEP 36570-000, Departamento de Nutrição e Saúde, Campus UFV, Viçosa, Minas Gerais, Brasil.

E-mail: rribeiroळufv.br

\section{Rosângela Minardi Mitre Cotta}

Doutora em Saúde Pública. Professora Associada do Departamento de Nutrição da Universidade Federal de Viçosa.

Endereço: Av. PH Rholfs, s/n., CEP 36570-000, Departamento de Nutrição e Saúde, Campus UFV, Viçosa, Minas Gerais, Brasil.

E-mail: rmmitreळufv.br

\section{Resumo}

A fome, as carências nutricionais específicas e todas as outras formas de manifestação de insegurança alimentar não são fenômenos recentes, assim como a preocupação em estancá-las. Para tanto, ao longo dos anos, o conceito de segurança alimentar e nutricional foi reformulado e ampliado, e a atual concepção prima não somente por preservar, mas ampliar o princípio de controle social na formulação e no monitoramento das ações de segurança alimentar e nutricional. $\mathrm{O}$ objetivo deste estudo foi avaliar o controle social do Conselho de Segurança Alimentar e Nutricional do Espírito Santo em relação à política estadual de SAN, por meio da análise de seu regimento interno; das deliberações contidas nas atas das reuniões ordinárias e extraordinárias do conselho e da avaliação complementar da frequência dos conselheiros representantes das entidades. Observou-se uma predominância de deliberações sobre a organização da estrutura e dinâmica interna e informe, em relação às deliberações sobre o monitoramento, as propostas e as ações de SAN. Constatou-se também quantidade significativa de ausências dos conselheiros representativos das entidades civis e do estado nas reuniões do conselho. Conclui-se que embora o Conselho se constitua em uma importante estratégia de controle social na realização das políticas de SAN no Estado, essa participação ainda não tem sido realizada de forma plena.

Palavras-chave: Segurança Alimentar e Nutricional; Conselhos; Controle Social. 


\section{Abstract}

Hunger, specific nutritional needs and all other forms of expression of food insecurity are not recent phenomena, nor is the concern about stanching them. The Food and Nutritional Security concept was reformulated and expanded over the years, and its current form aims not only to preserve, but also to expand the principle of social control regarding the formulation and monitoring of Food and Nutritional Security actions. The purpose of this study was to evaluate the social control of the Food and Nutritional Security Council of the State of Espírito Santo in relation to the FNS state policy, through the analysis of its internal regulations; the deliberations contained in the minutes of ordinary and extraordinary meetings of the council; and additional evaluation of the attendance of the entities' representatives. The predominance of deliberations about the organization of the structure and internal dynamics was observed, as well as reports on deliberations about the monitoring, proposals and FNS actions. There was also a significant amount of absences of civil and state entities' representatives at council meetings. It follows that although the Council represents an important strategy of social control in the pursuit of FNS state policies, this participation has not yet been fully carried out.

Keywords: Food Security and Nutrition; Councils; Social Control.

\section{Introdução}

A fome, as carências nutricionais específicas e muitas outras formas de manifestação de insegurança alimentar não são fenômenos recentes, assim como a preocupação em estancá-las. Entretanto, em âmbito internacional, a noção de Segurança Alimentar emerge apenas no contexto histórico no qual a disponibilidade e o acesso aos alimentos se converteram numa questão de segurança das populações e dos estados a ser promovida por meio da adoção sistemática e permanente de políticas públicas. Foi no contexto de duas guerras mundiais e da recessão dos anos 1930, nas primeiras décadas do século XX, que a questão alimentar tornou--se uma tarefa de estado (Maluf, 2007).

Assim sendo, inicialmente, a compreensão de segurança alimentar se restringia à preocupação com o aumento da disponibilidade de alimentos com vistas a preservar a própria segurança do estado. Contudo, a mecanização agrícola, a produção de alimentos em escala industrial e a expansão de relações internacionais de natureza política e econômica mais complexa evidenciaram o caráter dinâmico do conceito, revelando progressivamente que a questão do acesso, da inocuidade, da sustentabilidade e do respeito à diversidade cultural também são determinantes para que ocorra Segurança Alimentar e Nutricional (SAN).

No Brasil, concordando com recorte realizado por Maluf (2007), considera-se que o tema surgiu com maior repercussão na década de 1940 com a publicação do livro Geografia da Fome, de Josué de Castro. A obra denunciava a situação da fome, entendida como resultado de fatores multicausais, com ênfase na falta de acesso devido às desigualdades sociais.

Hoje, o tema ganhou status legal, a Lei Orgânica de Segurança Alimentar e Nutricional (LOSAN) - lei N. 11.946 de 15 de setembro de 2006 -, que cria o Sistema Nacional de Segurança Alimentar e Nutricional (SISAN), no art. $3^{\circ}$, define que

a segurança alimentar e nutricional consiste na realização do direito de todos ao acesso regular e permanente a alimentos de qualidade, em quantidade suficiente, sem comprometer o acesso a outras necessidades essenciais, tendo como base práticas alimentares promotoras de saúde 
que respeitem a diversidade cultural e que sejam ambiental, cultural, econômica e socialmente sustentáveis (Brasil, 2006).

Essa concepção amplia os desafios no estabelecimento das políticas e ações de SAN, na medida em que impõe que elas se deem em bases sustentáveis, de forma intersetorial e respeitando a soberania nacional. Esse conceito, construído coletivamente ao longo das duas últimas décadas em espaços democráticos como as conferências e encontros internacionais e nacionais, deve, na sua aplicação, não somente preservar, mas ampliar a participação e o controle social. Dentre os princípios do SISAN explicitados na LOSAN, o Art. $8^{\circ}$ destaca a importância da participação social na formulação, na execução, no acompanhamento, no monitoramento e no controle das políticas e dos planos de segurança alimentar e nutricional em todas as esferas de governo (Brasil, 2006).

Ressalta-se que o controle social sobre políticas públicas no Brasil emergiu no contexto de falência do sistema político ditatorial iniciado em meados de 1970. Naquele contexto, a crise econômica, somada à insuficiência e ineficiência das políticas públicas sociais vigentes, resultou em condições precárias de vida de parcela significativa da população e desencadeou um movimento de reforma política com vistas à democratização das ações do estado para atendimento efetivo das demandas sociais.

A perspectiva emergente, segundo Lumbambo e Coutinho (2004), era de que a abertura do estado para a participação concreta dos segmentos populares no processo decisório seria condição básica para efetiva gestão, onde os recursos seriam destinados com mais eficiência e com controle mais amplo. Segundo Cotta e colaboradores (1998), as reformas sociais propostas na Nova República traziam implícito o diagnóstico de que o modelo de crescimento com desigualdade, autoritarismo e excessiva centralização do poder haviam bloqueado as demandas populares. Emergia ainda a compreensão de que a participação da sociedade civil organizada reforçaria a dinâmica social no sentido da sua organização em associações de interesse, facilitando a disseminação da cultura participativa própria de uma comunidade cívica, que encontra na justiça, na equidade, na solidariedade, na confiança e na tolerância seus princípios fun- damentais (Labra, 2002 apud Martins e col., 2008). Justificando ainda a criação dessas instâncias de controle social, estaria a perspectiva ideológica de que os atores sociais de diferentes segmentos, com seus respectivos interesses, ao se reunirem, buscariam soluções consensuais com vistas ao bem-estar coletivo.

Pode-se inferir que tais pressupostos fundamentam-se na doutrina clássica da democracia criticada por Schumpeter (1961), na qual o método democrático é compreendido como um arranjo institucional para se chegar a decisões políticas que realizem o bem comum, cabendo ao próprio povo decidir, através da eleição de indivíduos que se reúnem para cumprir-lhe a vontade. Essa compreensão do método democrático, ainda segundo esse autor, pressupõe a existência de um bem comum que seja orientador da política, fácil de definir e de entender por todos os membros da sociedade. Pressupõe também que há uma vontade comum, que corresponde exatamente ao interesse, ao bem-estar ou à felicidade comuns. Por conseguinte, todos os membros da comunidade, conscientes da meta, sabendo o que querem, discernindo o que é bom do que é mau, tomam parte, ativa e honestamente, no fomento do bom e no combate ao mau. É com base nesses pressupostos que no sistema democrático os membros, em conjunto, controlariam os negócios públicos.

Dentro dessa perspectiva da democracia clássica é que a sociedade civil adquiriu importância significativa não apenas na luta contra o autoritarismo, mas também no estabelecimento de novas práticas e valores sociais pautados na igualdade, na solidariedade, na cultura de direitos e na constituição de novos mecanismos de gestão de políticas públicas (Lüchmann, 2002).

Dessa forma, em diversos setores da nova configuração de estado democrático emergiram diferentes níveis e arenas de participação social, dentre os quais se incluem, por exemplo, as comissões, os fóruns, as conferências, os conselhos gestores. Estes últimos ocupando posição privilegiada, uma vez que passam a fazer parte, inclusive, em caráter obrigatório, da estrutura institucional de diversas políticas públicas sociais.

Conforme assinala Tatagiba (2005), os conselhos gestores estão presentes na maioria dos municípios 
brasileiros, abrangendo diversos setores: saúde, educação, moradia, dentre outros. Representam uma conquista inegável da construção de uma institucionalidade democrática que intensifica o diálogo entre governo e sociedade e propicia condição para a alocação mais justa e eficiente dos recursos públicos.

Entretanto, diversos estudos sobre conselhos gestores têm demonstrado que a ideia da participação da sociedade civil não assegura por si mesma a reversão de uma lógica de poder em direção ao aprofundamento da democracia. Segundo Lüchmann (2002), é preciso atentar para o fato de que os fatores impeditivos de processos participativos são complexos, envolvendo questões de natureza política, econômica, social e cultural, e que dizem respeito a uma sociedade estruturalmente assentada sobre os pilares do clientelismo, do autoritarismo e das desigualdades sociais.

Seguindo essa mesma linha de raciocínio, Lumbambo e Coutinho (2004) apontam a ocorrência de três fatores impeditivos do efetivo controle social:1) a persistência de práticas clientelistas, autoritárias e de corrupção na trajetória política brasileira; 2) a predominância de uma cultura individualista de defesa de interesses particulares, que impede o comprometimento legítimo dos indivíduos nos fóruns de controle social; 3) a suspeita de que há um restrito capital social aprimorado, tecnicamente habilitado para atuar como partícipe de uma gestão social, o que levaria a uma frágil atuação dos conselhos.

Além dessas limitações, é significativo considerar a Teoria da Ação coletiva desenvolvida por Olson. De acordo com essa teoria, a capacidade de organização dos interesses dos diferentes segmentos sociais impõe distorções no mecanismo de representação, onde nem todos os atores conseguem obter o mesmo grau de representação de seus interesses (Olson, 1965 apud Cotta e col., 1998).

Deve-se também considerar as análises sobre cidadania efetuadas por Bobbio (1986). Segundo esse autor, é necessário reconhecer o contraste existente entre os ideais democráticos e a "democracia real”. Nesta última, observa-se uma série de “promessas não cumpridas", entre elas a crença de que a educação para a democracia surgiria do próprio exercício democrático. Ao analisar a cultura da participação democrática em instâncias representativas infere-se que ela pode ser compreendida por meio dos conceitos de output e input do sistema político. $\mathrm{O}$ output do sistema refere-se aos benefícios que o eleitor espera extrair do sistema político, e o conceito de input é relativo à cultura participante, própria dos eleitores potencialmente empenhados na articulação das demandas e na formação das decisões. Segundo esse autor, mesmo nas democracias consolidadas está diminuindo o voto de opinião, e aumentando o voto clientelar fundado no apoio político em troca de favores pessoais, orientado para o output. Embora as análises desse autor se reportem ao exercício da cidadania no momento de eleição de seus representantes, pode-se supor que esse comportamento orientado para o output se repita em outras arenas de participação social, tais como os conselhos gestores.

Os estudos supracitados sobre o processo de constituição do estado democrático e das instâncias e estratégias de participação social nele existentes conduzem ao questionamento do exercício do controle social no âmbito do SISAN, e suscitam a hipótese norteadora deste trabalho de que, embora os Conselhos de Segurança Alimentar e Nutricional (CONSEAs) sejam compreendidos como uma importante estratégia de controle social na realização das políticas de SAN, a sua atual estrutura de organização, interatividade e dinâmica de funcionamento faz com que esse controle social seja ainda incipiente.

O objetivo deste trabalho foi analisar o controle social do Conselho de Segurança Alimentar e Nutricional do Espírito Santo (CONSEA/ES) em relação à política estadual de SAN.

No âmbito da SAN, juntamente com as Conferências, o Fórum Brasileiro de Segurança Alimentar e Nutricional (FBSAN) e os CONSEAs constituem-se em esferas institucionais do SISAN para a realização do controle social. São instâncias de caráter predominantemente consultivo, que aglutinam representantes do governo e da sociedade civil com papel de assessoramento do estado na formulação e implementação das políticas de SAN.

Importante ressaltar que os conselhos não se constituem em instâncias peculiares do SISAN, outros sistemas ou setores, inclusive anteriores a ele, tais como a Saúde e a Educação, mas recorreram à 
instituição de conselhos como mecanismo de controle social. A peculiaridade dos conselhos no SISAN reside, entre outros aspectos, no fato de não estarem necessariamente subordinados a um ministério ou secretaria estadual ou municipal, assumindo um caráter suprassetorial, e de serem órgãos de composição majoritária de membros representantes da sociedade civil em relação aos representantes do governo do estado na proporção de $2 / 3$ e 1/3, respectivamente de cada segmento.

Dentre as características comuns fundamentais com os demais conselhos está o fato de que foram concebidos dentro da mesma premissa de constituição de sujeitos democráticos com o propósito de atuar em políticas públicas, em geral, do tipo distributiva.

Conforme formulado por Theodor Lowi, 1972 citado por Souza (2004), as políticas redistributivas são aquelas nas quais as decisões tomadas pelo governo desconsideram a questão dos recursos limitados, gerando impactos mais individuais do que universais, ao privilegiar certos grupos sociais ou regiões, em detrimento do todo. Por privilegiar certos grupos, o desenho estratégico dessas políticas deve incluir a identificação dos atores que lhes deem sustentação e os mecanismos de articulação e negociação entre tais atores. Sem tais atores, as políticas públicas de caráter redistributivo, como os programas na área social, tendem a se sustentar apenas na adesão fortuita e muitas vezes oportunista de setores das burocracias especializadas, o que lhes confere pouca legitimidade social e baixa sustentabilidade (Luchmann, 2002).

A criação do primeiro CONSEA deu-se em abril de 1993, no governo do então presidente Itamar Franco, e era um órgão de consulta e assessoria do Presidente da República, composto dos ministros de Estado e representantes da sociedade civil. Segundo Maluf (2007), na época emergiu como uma forma inovadora de parceria na busca de soluções para o problema da fome e da miséria no país, mas que durou apenas até o final de 1994 quando foi extinto pelo governo Fernando Henrique Cardoso. Para esse autor, quatro fatores contribuíram para que os êxitos alcançados fossem limitados: a novidade do tema, o caráter de transição do governo Itamar, a zelosa resistência dos controladores da política econômica e a frágil atuação da maioria dos conselheiros, tanto oriundos do governo quanto da sociedade civil. Para Maluf, "a débil repercussão da extinção do conselho confirma o limitado enraizamento social daquela primeira e breve experiência" (2007, p. 84).

Em março de 2003, o então Presidente da República, Luiz Inácio Lula da Silva, restituiu e deu posse aos membros do novo CONSEA nacional, permanecendo como um órgão de assessoramento da Presidência da República composto dos ministros de Estado, representantes da sociedade civil e das entidades empresariais, além de observadores de outros conselhos, organismos nacionais e internacionais. A ideia de constituição do conselho se multiplicou e deu origem a conselhos estaduais e municipais, sendo que atualmente estes somam um total de 27 conselhos estaduais e 253 municipais, respectivamente, presentes em todo o território nacional e ampliando as probabilidades de controle social (CONSEA, 2007).

\section{Metodologia de Investigação}

O CONSEA/ES, objeto de estudo desta investigação, foi instituído pelo Decreto ${ }^{\circ} 1141-S$, de 29 de maio de 2003, com o objetivo de propor políticas estruturantes que configurem a alimentação como um dos direitos humanos fundamentais e como parte integrante do direito de cada cidadão, assim como promover e/ou articular ações supletivas em caráter de emergência, destinadas a determinados grupos sociais, voltadas para o enfrentamento do problema da fome e da miséria (Espírito Santo 2003 a).

O CONSEA/ES é constituído, de acordo com diretrizes do CONSEA Nacional, por 1/3 de representantes do Governo do Estado e 2/3 de representantes da Sociedade Civil organizada, sendo que estes não recebem qualquer tipo de remuneração por ser a participação no Conselho considerada função pública relevante. 0 primeiro mandato dos conselheiros ocorreu no período de 2003 a 2006, e o segundo, de dois anos, no período de 2000 a 2008 , conforme previsto no Regimento Interno elaborado e aprovado em 31 de agosto de 2006 pelos conselheiros do mandato anterior (CONSEA/ES 2006).

Ainda de acordo com o exposto regimento Interno, compete ao CONSEA/ES: 1) propor diretrizes, 
aprovar, acompanhar e controlar a execução do Plano Estadual de Segurança Alimentar e Nutricional; 2) articular os órgãos do governo federal, estadual e municipal e organizações não governamentais para a implantação desse plano; 3) propor e apoiar ações voltadas para o combate às causas da miséria e da fome; 4) incentivar parcerias que garantam mobilização e racionalização no uso dos recursos disponíveis; 5) coordenar campanhas de conscientização da opinião pública, visando articular a união de esforços; 6) criar Câmaras Temáticas para estudo e acompanhamento permanente de temas fundamentais na área de SAN (CONSEA/ES, 2006).

Para a análise do controle social no contexto do CONSEA/ES, investigou-se o conteúdo das atas e as memórias de atas de reuniões do plenário do CONSEA/ES realizadas durante o período de 13 de novembro de 2003 a 17 de abril de 2007 , totalizando 29 documentos analisados.

Três fatores fundamentais justificaram a ênfase no conteúdo das atas das reuniões do plenário: primeiro, o fato de o plenário constituir-se a instância máxima do conselho com atribuições deliberativas em relação à política de SAN, onde a presença ativa dos conselheiros é considerada parte de suas competências; segundo, porque é nas reuniões do plenário que ocorre a interação dos diferentes segmentos sociais, onde os conselheiros se encontram, discutem, negociam, disputam e votam as matérias referentes a SAN. As propostas aprovadas, pelo fato de raramente apresentarem unanimidade consensual, expressam o jogo de forças, os interesses e as posições majoritárias; e terceiro, porque as deliberações do Plenário são convertidas em Resoluções, posteriormente publicadas no Diário Oficial, e expressam a concretização do cumprimento ou não das diretrizes da política de SAN.

Nesta pesquisa as deliberações contidas nas atas foram distribuídas em cinco categorias de análise, a saber: 1) Informes; 2) Organização e Dinâmica Interna; 3) Monitoramento e Controle das Políticas de SAN; 4) Proposições; 5) Ações de SAN. Também foi realizada análise quantitativa da situação das atas em relação à apreciação e aprovação pelo plenário, levantando-se quantas atas foram aprovadas ou não. Em caráter complementar ao conteúdo das atas foi avaliada a assiduidade dos segmentos repre- sentativos - sociedade civil e estado - nas reuniões do plenário. Realizou-se a soma das presenças e faltas de todas as entidades representantes dos dois segmentos em cada ano. Nessa análise foram consideradas somente como faltas as ausências dos conselheiros representantes titular e suplente do mesmo segmento, pois considerou-se que, na presença de um deles, a representação por segmento estava garantida.

\section{Resultados}

Seguindo o critério de distribuição das categorias de análise acima descritas, inicia-se esta discussão a partir dos Informes. Ressalta-se que foram considerados como Informes as deliberações que comunicam sobre eventos com interface na área de SAN, com ou sem a participação do CONSEA, por exemplo, as deliberações tipo: 1) "Será realizado no dia 19 de março de 2004 o evento economia solidária e desenvolvimento" ( 3 a Reunião Ordinária -26/o2/2004); 2) "Lançamento no Estado do Programa Cozinha Brasil, do SESI" (6ª Reunião Ordinária - 29/o7/2004). De acordo com o gráfico 1, os Informes representaram $41 \%$ das deliberações.

\section{Gráfico I - Deliberações realizadas pelos membros do Conselho de Segurança Alimentar e Nutricional do Es- tado do Espírito Santo no período de 2003 a 2007}

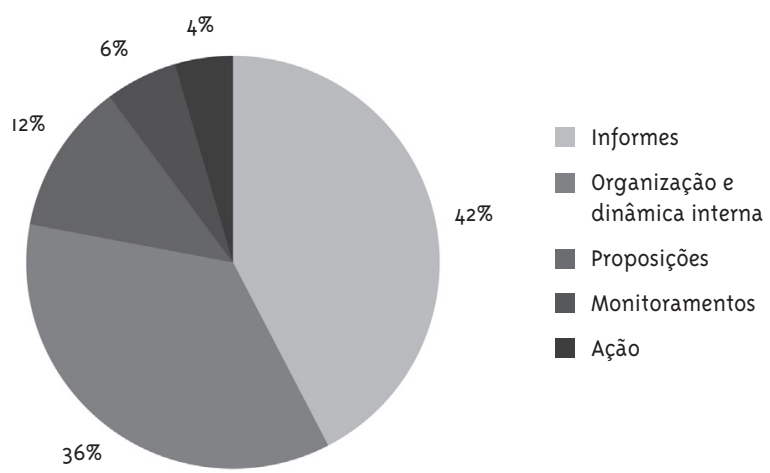

Na categoria Organização e Dinâmica Interna foram reunidas aquelas deliberações que se referem à estrutura de funcionamento e operacionalização do CONSEA, incluindo desde o processo de eleição até a organização das Conferências de SAN, como pode 
ser visto nos exemplos a seguir: 1) "Formação de comissão para elaboração de proposta do regimento interno, [e] comissão para preparação da Conferência Estadual” (1 ${ }^{\text {a }}$ Reunião Ordinária -13/11/2003); 2) "Realização das reuniões às quintas-feiras, por ser o dia em que o auditório da Secretaria de Estado do Trabalho e Ação Social (SETAS) está mais disponível" (3 ${ }^{a}$ Reunião Extraordinária - 17/12/2003); 3) “Votar os nomes dos representantes deste CONSEA no I Encontro de CONSEAs Estaduais da Região Sudeste" (8 Reunião Ordinária - 04/11/2004). As deliberações dessa natureza contemplaram 36\% do total, somente ficando atrás dos Informes. Somados, deliberações tipo Informe e Organização e Dinâmica Interna perfazem $77 \%$ do conjunto das deliberações.

Observou-se certa morosidade no fluxo das atividades de organização e operacionalização do Conselho, haja vista a recorrência de determinadas deliberações nas reuniões, conforme fica explícito nos exemplos a seguir: 1) "Retomar o tema Regimento Interno na próxima reunião" ( $3^{\text {a }}$ Reunião Ordinária - 26/02/2004); 2) “Agilizar a discussão do

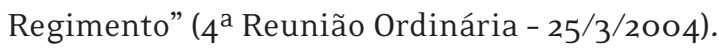

Em relação à dinâmica do CONSEA/ES, também chamou a atenção a irregularidade em relação ao número de reuniões realizadas em cada ano durante o período de 2003 a 2007. No mandato inaugural do CONSEA/ES, publicado no Decreto $\mathrm{n}^{\circ}$ 2051-S em 31 de outubro de 2003 , ocorreram 4 reuniões (1 ordinária e 3 extraordinárias), sendo que a primeira reunião ocorreu em novembro do referido ano (Espírito Santo 2003 b).. No ano de 2004, esse total foi de 10 reuniões (7 ordinárias e 3 extraordinárias); em 2005 foram 7 reuniões (todas ordinárias); em 2006 foram 3 (todas ordinárias); e, em 2007, 3 ordinárias e 2 extraordinárias, ressaltando que no ano de 2007 as atas foram analisadas somente até abril. Além da não equivalência no número de reuniões, constata-se que, até 2006, elas ocorreram em número inferior ao preconizado no Regimento Interno deste conselho onde consta que "O plenário reunir-se-á em caráter ordinário, uma vez por mês e extraordinariamente, sempre que for convocado pelo presidente, ou por 2/3 de seus membros" (CONSEA/ES, 2006, p. 4). A irregularidade das reuniões pode, inclusive, ser uma entre outras causas da recorrência de alguns temas e a não conversão de algumas proposições em ações concretas como veremos na análise das categorias de proposições e ações mais adiante.

Considerou-se como Monitoramento e Controle das Políticas de SAN o diagnóstico e acompanhamento dos impactos dessas políticas sobre a população, principalmente aquelas voltadas para os grupos mais vulneráveis. Nesse sentido, essa categoria incorporou deliberações como: 1) "Apresentação da Associação de Celíacos do Espírito Santo - ACELES, justificando a importância da discussão da temática no CONSEA-ES" (8 $8^{a}$ Reunião Ordinária - 04/11/2004); 2) "Apoio aos povos indígenas no desenvolvimento de ações de SAN" (12 ${ }^{\text {a }}$ Reunião Ordinária - 28/04/2005).

Podemos ver, pelo gráfico 1, que essas deliberações representaram somente 6\% do total, a despeito do fato de elas serem essenciais para o andamento das políticas de SAN e superação das situações de insegurança alimentar e nutricional a que está sujeita parcela significativa da população. Ademais, o conteúdo das atas indica que inexistem, até o momento da pesquisa, procedimentos e instrumentos concretos de sistematização das ações de Monitoramento, o que implica que elas têm se processado de forma difusa. Contudo, há, no Regimento Interno, a proposta de criação de Câmaras Temáticas Permanentes com o objetivo de sistematizar e aprimorar as competências do CONSEA/ES. Essas câmaras deveriam elaborar pareceres, estudos e relatórios a serem apreciados e aprovados em plenário. Entre as câmaras citadas no Regimento, está prevista a composição de uma Câmara de Indicadores, Instrumentos de Ação, Avaliação e de Monitoramento de SAN, mas que até o final desta pesquisa não havia sido implementada (CONSEA/ES, 2006).

No conjunto, as Proposições incluíram as propostas elaboradas pelos membros do CONSEA com intuito de assessorar o Governo do Estado e entidades da sociedade civil na elaboração e implementação de ações de SAN. Essas propostas, a princípio, se formulariam em cumprimento ao papel do CONSEA previsto na LOSAN e no Regimento Interno. Como propostas foram classificadas, entre outras, as seguintes deliberações: 1) "Importância de fazer mapeamento sobre a situação de insegurança alimentar no estado e propõe que seja apresentado na próxima reunião o Sistema de Vigilância Alimentar 
e Nutricional (SISVAN) ao CONSEA/ES" (5 Reunião Ordinária - 24/o6/2004); 2) "Aprofundar a discussão sobre a terceirização da alimentação escolar" ( $6^{\text {a }}$ Reunião Ordinária - 29/o7/2004); 3) "Formação de uma comissão de trabalho temporário para análise técnica e emissão de parecer sobre multimistura a ser apresentada ao governo antes da celebração do convênio entre a Pastoral da Criança e o Governo do Estado" (6ª Reunião Ordinária - 29/07/2004).

Apesar de sua relevância na elaboração das políticas de SAN estaduais, essas deliberações propositivas representaram somente $12 \%$ do total.

Dentro da categoria Ações, avaliaram-se as deliberações em que as proposições se converteram em ações concretas de SAN, como exemplo: 1) "Apresentação do sistema SISVAN, como ele vem sendo implantado no estado" (6 ${ }^{a}$ Reunião Ordinária - 29/07/2004); 2) "Apresentação e aprovação de documento com proposta sobre a multimistura" ( $5^{\mathrm{a}}$ Reunião Extraordinária - 05/o8/2004). Essas duas deliberações acataram a proposta da $5^{\text {a }}$ e $6^{\text {a }}$ reuniões ordinárias de 2004, respectivamente. Na análise, essas Ações representaram $5 \%$ do conjunto, como mostra o gráfico 1. Quando comparada à porcentagem de Proposições (12\%), indica que mais de $50 \%$ das Propostas não se converteram em Ações.

O gráfico 2 representa uma distribuição do conjunto das deliberações de acordo com a cinco categorias estabelecidas no período da pesquisa. Revela que durante todo o período analisado predominaram as deliberações sobre Organização e Dinâmica Interna e Informe, que houve uma significativa prevalência de informes no período de 2005 a 2006, e praticamente uma ausência de deliberações sobre monitoramentos e ações no período de 2006 a 2007. Durante a pesquisa foi também diagnosticado o fato de os conselheiros não terem participado de nenhum processo de capacitação para a realização de suas funções.

\section{Gráfico 2 - Deliberações realizadas pelos membros do Conselho de Segurança Alimentar e Nutricional do Es- tado do Espírito Santo no período de 2003 a 2007.}

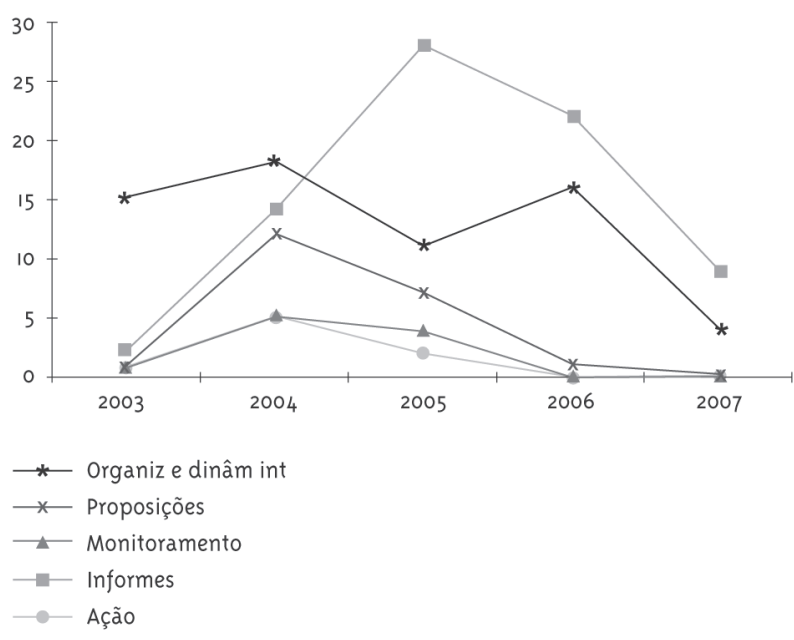

Na análise das atas, buscamos verificar se todas elas foram aprovadas ou não. Tomando por base o total de 29 documentos analisados, chegamos ao resultado de que $66 \%$ deles não foram aprovados pelos conselheiros presentes nas reuniões, conforme o gráfico 3 .

Gráfico 3 - Porcentagem de atas aprovadas e sem aprovação pelo Conselho de Segurança Alimentar e Nutricional do Estado do Espírito Santo, no período de 2003 a 2007

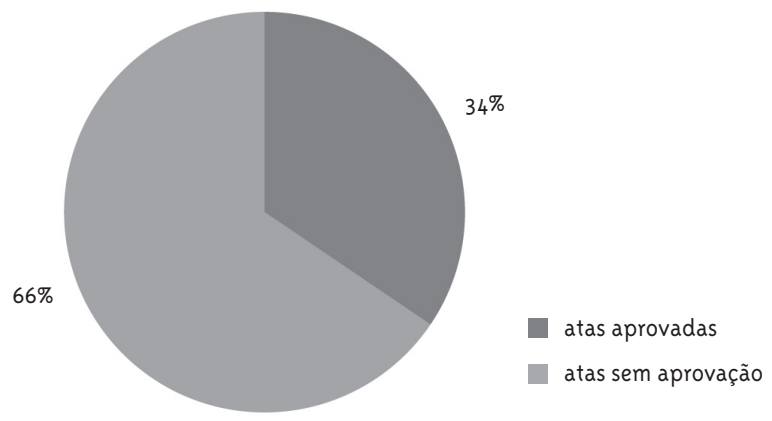


Nota-se na avaliação das atas que muitas foram enviadas por correio eletrônico aos conselheiros para serem analisadas, conforme ilustra a seguinte fala: "Foi acordado entre os presentes que as três atas seriam enviadas pela secretária executiva para os conselheiros, via $e$-mail, para apreciação, e que esses redigiriam e enviariam ao CONSEA a possível proposta de alteração das atas" (18 $8^{\text {a }}$ Reunião Ordinária - 26/10/20o6). Um dos possíveis motivos da não aprovação pode ser o fato de alguns conselheiros relatarem não ter lido as atas por não possuírem acesso à internet, ou por essas atas não terem sido enviadas em tempo hábil para apreciação. Cabe ressaltar que as atas que não são aprovadas em reunião não são formalmente validadas, mas isso não implica, necessariamente, em que as deliberações sejam descumpridas.

A tabela 1 refere-se à representação dos órgãos governamentais e segmentos da sociedade civil. Demonstra que em todos os anos houve uma maior participação dos representantes da sociedade civil nas reuniões. Isso pode ser justificado por haver uma maior representação da sociedade civil (2/3) na composição do CONSEA em relação aos órgãos governamentais (1/3).

\section{Tabela I - Frequência das entidades do governo e sociedade civil nas reuniões do Conselho de Segurança Ali- mentar e Nutricional do Estado do Espírito Santo, 2007}

\begin{tabular}{lcccc} 
& \multicolumn{2}{c}{ Órgãos Covernamentais } & \multicolumn{2}{c}{ Representantes da Sociedade Civil } \\
ANO & $N^{0}$ de Faltas & $N^{0}$ de Presenças & $N^{0}$ de Faltas & $N^{0}$ de Presenças \\
2003 & 13 & 19 & 36 & 28 \\
2004 & 32 & 48 & 83 & 77 \\
2005 & 29 & 27 & 51 & 61 \\
2006 & 10 & 14 & 16 & 32 \\
2007 & 11 & 29 & 20 & 60 \\
\hline
\end{tabular}

Por último, destaca-se que todas as entidades apresentaram um grande número de ausências nas reuniões, o que também explica a dificuldade de avançar nas deliberações. Ata da $10^{a}$ Reunião Ordinária, de 24 de fevereiro de 2005, expressa a preocupação da mesa diretora quanto à baixa participação dos conselheiros nas reuniões, determinando, inclusive, o envio de ofício de advertência às entidades cujos representantes não têm comparecido. Na plenária em questão, a mesa reconheceu ser fundamental a participação dos conselheiros para que sejam efetuadas as deliberações e para o bom andamento das atividades do conselho.

\section{Discussão}

Analisando os resultados apresentados, chama a atenção a preponderância de deliberações das categorias Informes (41\%) e Organização e Dinâmica internas (36\%). Em relação à primeira categoria, compreende-se que os informes têm sua relevância pelo fato de que, além de comunicar sobre os eventos, eles estimulam a participação dos conselheiros e, por essa via, servem para divulgar o papel do CONSEA para a sociedade em geral. Contudo, o fato de se revelarem em maior número e empregando uma maior parte do tempo nas reuniões contraria o Regimento Interno que preconiza que as competências do conselho devem estar prioritariamente voltadas para a proposição, a análise, o monitoramento e o apoio das ações e programas públicos relacionados a SAN sob a ótica dos direitos humanos (CONSEA/ ES, 2006).

No que tange a categoria Dinâmica e Organização interna, situação similar foi diagnosticada por Lüchmann (2002) ao estudar o desenho institucional dos Conselhos de Saúde. Essa autora constatou que a elaboração do regimento interno ocupa as pautas de reuniões por meses ou até anos consecutivos. Esse tipo de atividade foi analisado como um fator que contribui para o recrudescimento de uma atuação eminentemente institucional dos conselheiros que 
não assegura uma maior articulação e participação com suas bases sociais representativas.

Conjuntamente essas duas categorias representaram $77 \%$ das deliberações. Compreende-se que sejam determinadas por diversos fatores; entre eles, a própria precocidade do CONSEA/ES. A partir de estudo focado na instância nacional, Costa (2008) destaca que a experiência do CONSEA, diferentemente dos Conselhos de Saúde que possuem significativa legitimidade perante a sociedade e os governos, é relativamente recente, encontrando-se em estágio inicial de desenvolvimento. Essa assertiva sobre a precocidade do CONSEA é ainda mais válida para as instâncias municipais e estaduais.

Passando à análise das categorias Monitoramento e Controle das Políticas de SAN (6\%); Proposições (12\%) e Ações (5\%), elas serão discutidas conjuntamente, porque embora sejam categorias de sentido distinto, conforme explicitado acima, possuem uma estreita relação de dependência, pois espera-se que as proposições sejam formuladas mediante indicadores de monitoramento, que deveriam se converter em ações, que, por sua vez, também deveriam ser avaliadas por meio dos indicadores de monitoramento, fechando um ciclo contínuo de interatividade entre essas três categorias.

Os resultados revelaram, tanto isoladamente quanto em conjunto, um percentual minoritário de deliberações de Monitoramento, Propositivas e de Ações, inclusive observando-se que poucas proposições se converteram em ações efetivas, quando comparadas à porcentagem de Proposições (12\%). Os resultados indicam que mais de 50\% das Propostas não se converteram em Ações.

Compreende-se que esse cenário amplia as possibilidades de violação do DHAA e enfraquece a participação social na formulação, implementação e fiscalização das políticas de SAN. Conforme analisado no início deste trabalho, o objetivo da participação social é a universalização dos direitos sociais; a ampliação do conceito de cidadania; e a influência da sociedade no aparelho estatal com vistas ao melhor atendimento das demandas sociais (Souza, 2004). Compreende-se que essa influência, no âmbito do conselho, somente se concretiza via predominância de deliberações de natureza monitorativa e propositiva e da realização de ações efetivas promotoras da SAN.

Um fator importante a se considerar ao analisar a incipiente prevalência dessas três categorias de deliberações é o fato de os conselheiros não terem participado de nenhum processo de formação para a realização de suas funções. Essa ausência de formação não é, inclusive, privilégio do CONSEA/ES. Estudiosos da Associação Brasileira pela Nutrição e Direitos Humanos ${ }^{1}$ afirmam que diversos conselhos de políticas públicas no Brasil sofrem de uma série de problemas; entre eles, a ausência de capacitação dos conselheiros para o exercício de suas funções. Entende-se que esse processo de formação é condição necessária para o empoderamento dos conselheiros, ele possibilitaria muni-los de informações necessárias para que efetivamente pudessem avaliar e propor políticas de SAN.

Compreender como funciona a administração, quais os problemas e demandas sociais, quais as prioridades e mecanismos de atendimento, são algumas das questões que desafiam a participação junto aos Conselhos. Segundo Chauí, 1986 citada por Martins e colaboradores (2008), os sujeitos políticos participam da vida social em proporção ao volume e qualidade das informações que possuem, em especial a partir das suas possibilidades de acesso às fontes de informação e de condições favoráveis de aproveitamento delas, de forma a poderem intervir como produtores do saber.

Contudo, mesmo em face de um eventual processo de capacitação, deve-se retomar o conceito de output analisado por Bobbio (1986) e não desconsiderar a possibilidade de os membros representantes proporem ou votarem a favor de deliberações que atendam a seus interesses particulares, configurando uma situação de "mandato vinculado" típica da democracia real.

Igualmente devem ser consideradas as análises de Schumpeter (1961) acerca da natureza humana na política. Criticando os pressupostos da democracia clássica sobre a determinação e independência da

I ABRANDH - ASSOCIAÇÃO BRASILEIRA PELA NUTRIÇÃO E DIREITOS HUMANOS. Ausência e/ou ineficácia dos mecanismos de exigibilidade administrativos, quase judiciais e judiciais. Brasília, DF, 2007. Disponível em: <http://www.direitohumanoalimentacao.org.br>. Acesso em: 10 out. 2007. 
vontade do eleitor, seus poderes de observação e interpretação de fatos, e sua capacidade de tirar, clara e prontamente, inferências racionais de ambos, este autor recorre à psicologia social e às teorias econômicas sobre o consumo, que enfatizam acerca da importância do elemento irracional e extrarracional no comportamento dos indivíduos.

Primeiro, com base na psicologia das multidões, argumenta que, quando em aglomerações, os indivíduos agem com menor senso de responsabilidade, grau mais baixo de energia mental e maior sensibilidade a influências não lógicas. Segundo, a partir de análises econômicas sobre consumo, explica que existem dois tipos de racionalidades que guiam o comportamento humano e que atuam de acordo com as circunstâncias especificas: a racionalidade de pensamento e a racionalidade de ação. Esta ultima presente nas decisões frequentemente repetidas, em que o indivíduo é submetido à influência salutar e radonalizante de experiências favoráveis e desfavoráveis. São decisões que sofrem também a influência de motivos e interesses relativamente simples e sem problemas que deem motivos à inquietação (Shumpeter, 1961).

Isso é o que ocorre na maioria das decisões da vida diária, situadas dentro do pequeno campo que a mente do homem pode abarcar com inteira compreensão de sua realidade, nos fatos que lhe são familiares e que ele pode influenciar ou decidir diretamente e para as quais ele desenvolve uma espécie de responsabilidade, induzida por uma relação direta entre os efeitos favoráveis e desfavoráveis de um determinado curso de ação (Schumpeter, 1961). Importante frisar que para este autor a racionalidade de ação pode apresentarse sem qualquer deliberação consciente e à parte a habilidade de formular corretamente os motivos lógicos de ação. Em outros termos, a racionalidade de ação obtida por experiências cotidianas não implica em uma associação de causa/efeito.

Mesmo no caso de assuntos muitos próximos à realidade vivida, pode haver uma capacidade reduzida de discriminar, entre fatos, uma pequena disposição para agir neles baseado em um reduzido senso de responsabilidade.

No entando, quanto menores os vínculos diretos e quanto mais afastados são os assuntos dos interesses privados cotidianos, o conhecimento dos fatos e os métodos de inferência afastam-se mais ainda dos preceitos de responsabilidade e busca permanente do bem comum da doutrina clássica da democracia.

esse reduzido senso de realidade explica não apenas a existência de um reduzido senso de responsabilidade, mas também a ausência de uma vontade eficaz. 0 indivíduo fala, deseja, sonha, resmunga. E, principalmente, sente simpatias e antipatias. Mas, ordinariamente, esses sentimentos não chegam a ser aquilo que chamamos de vontade, o correspondente psíquico da ação responsável e intencional. De fato, o cidadão privado que medita sobre a situação nacional não encontra campo de ação para sua vontade nem tarefa em que ela possa se desenvolver (Schumpeter, 1961, p. 318).

Dentro dessa perspectiva, vale a pena indagar sobre o quão próximo o tema da (in)segurança alimentar, em toda a sua complexidade, que abarca temas como sustentabilidade, políticas intersetoriais e produção de alimentos, entre outros, suscitando-lhes um senso de responsabilidade e vontade de atuar em prol da causa, ainda diretamente vinculado a essa análise sobre a natureza humana na política, passa-se a discorrer sobre a representatividade dos segmentos (sociedade civil e estado) no CONSEA/ES.

Apesar de os dados da pesquisa terem revelado que em todos os anos houve uma maior participação dos representantes da sociedade civil nas reuniões, é importante ressaltar que a maior participação não implica necessariamente que as deliberações resultem na predominância do interesse dos mesmos. Diversos estudos têm demonstrado que nos conselhos a paridade numérica não corresponde a uma paridade política (Stanisci, 1997 apud Lüchmann, 2002). Mesmo entre as experiências que não obedecem à regra da paridade, como no caso dos CONSEAs, onde a sociedade civil predomina, observam-se muitas dificuldades para o estabelecimento de uma representatividade expressiva dos diferentes interesses sociais.

Para Cortes (2002), a posição das autoridades interfere decisivamente sobre a participação social, influenciando diretamente: (1) na formação da agenda de discussão, (2) no funcionamento geral do 
fórum, (3) na possibilidade de cumprir as decisões ali tomadas e (4) na possibilidade de pressionar os demais gestores e os prestadores de serviços para o cumprimento das decisões. Soma-se e esse problema a possibilidade de carência de legitimidade dos conselhos ocasionada pelo fato de muitos conselheiros serem designados por indicações políticas e não por meio de assembleias dos segmentos a que representam, não detendo, portanto, efetiva representação social. Essas indicações políticas corroboram com o pensamento de Olson, 1965 (apud Cotta e col., 1998) em relação às distorções da representatividade do controle social condicionadas pela capacidade de organização dos segmentos sociais.

Finalizando, observou-se também um expressivo número de atas não aprovadas e ausências de conselheiros nas reuniões de ambos os segmentos: sociedade civil e estado. Conforme ressaltado, as atas que não são aprovadas em reunião não são formalmente validadas, podendo implicar na execução das deliberações ou não. As faltas representam também um descompromisso.

\section{Considerações Finais}

Conclui-se que embora o CONSEA se constitua numa importante estratégia de controle social das políticas de SAN do Estado, no conselho estudado, esse controle revelou ser exercido de forma ainda incipiente. A evidência desse fato ficou expressa na predominância de deliberações de natureza informativa e sobre a organização da estrutura e dinâmica do Conselho, em relação às deliberações sobre monitoramento, proposição e ações de SAN. Somada a essa desproporcionalidade deliberativa, observou-se a irregularidade no número de assembleias no período analisado e o elevado número de faltas dos conselheiros.

Acredita-se que, no conjunto, esses fatores interferem mutuamente levando à fragilidade no desempenho do conselho. Nessa perspectiva, compreendese que a sobrecarga de discussões detalhadas sobre organização e informes leva ao esvaziamento de reuniões de conselho. Por sua vez, o elevado número de faltas acarreta a descontinuidade das discussões e, por consequência, impede o avanço das deliberações de natureza propositiva. 0 conteúdo das atas corroborou também a suspeita de que há um restrito capital social, aprimorado e tecnicamente habilitado, para atuar como partícipe de uma gestão social. Nesse sentido, ressalta-se a necessidade de realização de um processo de empoderamento dos conselheiros, para que estes obtenham condições de exercer o efetivo controle social das polícias de SAN no estado. Finalizando, ressalta-se que as análises contidas nesta pesquisa devem ser interpretadas considerando a escassez de publicações científicas sobre o tema, o que restringe a possibilidade de contrapor os dados obtidos a diferentes experiências e perspectivas. Essa lacuna teórica impõe, a princípio, a necessidade de mais estudos sobre o controle social no Sistema de Segurança Alimentar e Nutricional, seja no âmbito municipal, estadual ou nacional.

\section{Referências}

BOBBIO, N. O futuro da democracia: uma defesa das regras do jogo. Rio de Janeiro: Paz e Terra, 1986.

BRASIL. Lei ${ }^{\circ} 11.346$, de 15 de setembro de 2006. Cria o Sistema Nacional de Segurança Alimentar e Nutricional - SISAN com vistas em assegurar o direito humano à alimentação adequada e dá outras providências. Diário Oficial [da] República Federativa do Brasil, Brasília, DF, 18 SET. 2006. Disponível em: <http://www.planalto.gov.br/ ccivil_o3/_ato2004-2006/2006/Lei/L11346.htm>. Acesso em: 2 maio 2011.

CONSEA - CONSELHO NACIONAL DE SEGURANÇA ALIMENTAR E NUTRICIONAL. Consea. Disponível em: <http://www4.planalto.gov. br/consea/consea-2>. Brasília, DF, [s.d.]. Acesso em: 7 out. 2007 .

\section{GOVERNO DO ESTADO DO ESPÍRITO SANTO.}

Secretaria de Estado do Trabalho e Assistência e Desenvolvimento Social (SETADES). Conselho Nacional de Segurança Alimentar e Nutricional (CONSEA/ES). Regimento interno do Conselho de Segurança Alimentar e Nutricional do Estado do Espírito Santo - CONSEA/ES, de 31 de agosto de 2006. Diário Oficial do Espírito Santo, Vitória, 31 ago. 2006. p. 8. 
CORTES, S. M. V. Construindo a possibilidade da participação dos usuários: conselhos e conferências no Sistema único de Saúde. Sociologias, Porto Alegre, v. 4, n. 7, p. 18-49, 2002.

COSTA, C. G. A. Segurança alimentar e nutricional: significados e apropriações. 2008. Dissertação

(Mestrado em Saúde Pública)-Faculdade de Saúde Pública, Universidade de São Paulo, São Paulo, 2008.

COTTA, R. M. M.; MENDES, F. F.; MUNIZ, J. N. Descentralização das políticas públicas de saúde: do imaginário ao real. Viçosa: UFV, 1998.

ESPÍRITO SANTO. Decreto ${ }^{\circ} 1141$-S, de 29 de maio de 2003. Institui o Conselho de Segurança Alimentar e Nutricional do Estado do Espírito Santo e da outras providencias. Diário Oficial do Espírito Santo, Vitória, 29 maio 2003a. p. 2 ESPÍRITO SANTO. Decreto ${ }^{\circ}$ 2051S, de 30 de outubro de 2003. Designa os representantes para compor o Conselho de Segurança Alimentar e Nutricional do Estado do Espírito Santo CONSEA/ES. Diário Oficial do Estado do Espírito Santo, Vitória, 31 out. 2003b. p. 1.
LÜCHMANN, L. H. H. Os conselhos gestores de políticas públicas: desafios do desenho institucional. Ciências Sociais Unisinos, São Leopoldo, n. 161, p. 43-79, 2002.

LUMBAMBO, C. W.; COUTINHO, H. G. Conselhos gestores e o processo de descentralização. São Paulo em Perspectiva, São Paulo, v. 18, n. 4, p. 6272. 2004 .

MALUF, R. S. J. Segurança alimentar e nutricional. Petrópolis: Vozes, 2007.

MARTINS, P. C. et.al. Conselhos de saúde e a participação social no Brasil: os matizes da utopia. Physis, Rio de Janeiro, v. 18, p. 105-121, 2008.

SOUZA, R. O. Participação e controle social. In: SALES, M. A.; MATOS, M. C.; LEAL, M. C. (Org.). Política social, família e juventude: uma questão de direitos. São Paulo: Cortez, 2004. p. 167-187.

SCHUMPETER, J. A. Capitalismo, socialismo $e$ democracia. Rio de Janeiro: Fundo de Cultura, 1961.

TATAGIBA, L. Conselhos gestores de políticas públicas e democracia participativa: aprofundando o debate. Revista de Sociologia e Política, Curitiba, n. 25, p. 209-213, 2005. 